\title{
URBAN MICRO CLIMATE MODELLING USING DIFFERENT URBAN PHYISCS SCHEMES AND HIGH RESOLUTION LULC WITH WRF MODEL
}

\author{
Medisetti Bhavana ${ }^{1, *}$, Gupta Kshama ${ }^{2}$, Pal Pradip K ${ }^{1}$ \\ ${ }^{1}$ Centre for Space Science and Technology Education in Asia and the Pacific, Dehradun, India - (bhavana.m5678, \\ pradippal.sac)@gmail.com \\ ${ }^{2}$ Urban and Regional Studies Department, Indian Institute of Remote Sensing, Dehradun, India- kshama@iirs.gov.in
}

Commission V, SS: Atmosphere, Ocean, Weather and Climate

KEY WORDS: UCM, Urban physics, WRF Model, UBL

\begin{abstract}
:
Urban areas are treated as a single entity by mesoscale urban canopy models (UCM) for assessing the influence of urban morphology on climate. Weather Research and Forecasting Model (WRF) coupled with UCM along with urban physics options to describe the urban features such as Single Layer Urban Canopy Model (SLUCM), Building Energy Parameterization (BEP) and Building Energy Model (BEM) which enumerates the influence of urban features on the local scale other than the bulk parameterization (no urban physics option), which is generally used in most of the operational forecasting models. Besides, WRF model also enables to integrate multi-class Urban Land Use Land Cover (LULC) whereas most of the globally available LULC depict urban area as single urban built-up class. This study aims to analyze performance of high resolution urban LULC and urban physics options for Chandigarh area by downscaling climatic variables up to $1 \mathrm{~km}$ and its validation with the ground observation data. The inner domain $(1 \mathrm{~km}$ resolution) was configured with default LULC for one set of simulations and multi-class urban LULC for other set of simulations. All the simulations were carried out for 3 days (August 19-21, 2017) due to computational restrictions by employing all the four urban physics options. It has been found that multi-class urban LULC yielded better results than single class urban built -up simulation when validated with respect to ground observation. The RMSE values for multi-class urban LULC provided less RMSE than single class urban LULC, those are in terms of temperature at $2 \mathrm{~m}$, relative humidity and wind speed $\operatorname{are} 0.91^{\circ} \mathrm{C}, 2.63 \%$ and 1.82 $\mathrm{m} / \mathrm{s}$ respectively. Similarly, BEP+BEM urban physics option provided reduced RMSE values than the SLUCM and BEP scheme. The RMSE values in terms of temperature at $2 \mathrm{~m}$, relative humidity and wind speed are $1.11^{\circ} \mathrm{C}, 4.39 \%$ and $2.62 \mathrm{~m} / \mathrm{s}$ respectively.
\end{abstract}

\section{INTRODUCTION}

\subsection{Back ground}

More than half of the world's population (54 percent) now dwells in urban areas. Today there are over 400 cities in the world with populations of over 1 million (United Nations, 2007). The global urban population is estimated to grow by 2.5 billion urban inhabitants between 2014 and 2050, with nearly 90 per cent of the increase concentrated in Asia and Africa (UNDESA, 2014) alone.

Such a large scale human intervention with the natural environment has given rise to the phenomenon of Urban Heat Island (UHI) in which the temperature of the urban core is higher than the surrounding areas subject to calm weather conditions (Epa Chen \& EPA, 2008). According to the World Resources Institute (WRI), an international research organization, a major proportion of the world population will be subjected to frequent inland floods, rising sea levels, intense storms and more frequent periods of extreme hot and cold owing to climate change ("World' s 15 Countries with the Most People Exposed to River Floods," 2018).
Mean thermal and effects of the cities on the atmosphere can be estimated using urban parameterizations incorporated in numerical weather prediction (NWP) models. These models are executed with a grid spacing of $0.5-1 \mathrm{~km}$ for local and regional weather forecasts which provide input to air dispersion and pollution models. At such a fine horizontal resolution it becomes important to realistically represent the role of urban land use in local and regional weather.

Most of the operational forecasting activities, in Weather Research Forecast (WRF) model, a multi-agency effort for meso-scale weather prediction and data assimilation, represented urban area as a single entity which is known as bulk parameterization. In this scheme urban areas are of $0.8 \mathrm{~m}$, surface albedo of 0.15 , volumetric heat capacity of $3.0 \mathrm{~J} \mathrm{~m}-3$ $\mathrm{K}-1$ and thermal conductivity of $3.24 \mathrm{~W} \mathrm{~m}-1$ (Salamanca, Martilli, Tewari, \& Chen, 2011)

Later, WRF model has been integrated with Urban Canopy Models (UCMs) to quantify variations in urban areas

\footnotetext{
${ }^{*}$ Corresponding author
} 
at sub grid scale. Three urban physics options integrated in the model are: Single Layer Urban Canopy Model (SLUCM) (KUSAKA \& KIMURA, 2004), Building Energy Parameterization (BEP) and Indoor-Outdoor Exchange Model or Building Energy Model (BEM). SLUCM is a single layer model and was developed by Kusaka et al., 2004. It has simplified urban geometry which aggregates heat fluxes into energy and momentum exchange between the urban surface and the atmosphere. The urban geometry is represented through infinitely long street canyons, and three different urban surfaces (roof, wall, and roads) are recognized. On the other hand, BEP and BEM are multi-layer models. BEP distinguishes the three dimensional nature of urban surfaces. It takes into account of vertical and horizontal surfaces on urban areas and potential temperature. This scheme was developed by Chen et al., 2007 . The BEM scheme is coupled with BEP and it takes into account the exchange of energy between interior of the building and outdoor atmosphere. BEM accounts for the 1) diffusion of heat through the walls, roofs, and floors; 2) radiation exchanged through windows; 3) longwave radiation exchanged between indoor surfaces; 4) generation of heat due to occupants and equipments; and 5) air conditioning, ventilation, and heating. The BEP+BEM parameterization takes into account the exchanges of energy between the interior of the buildings and the outdoor atmosphere.

\subsection{Urban Area Representation in WRF Model}

As mentioned earlier, default global LULC layer considers urban built-up as a single class and does not account for urban heterogeneity. Tewari et al 2007 introduced three urban built-up classes in the LULC and used the layer as input in the UCM-WRF combine. The built-up classes taken were:

- 31. Low-Intensity Residential: Mixture of constructed materials and vegetation comes under this category. Built-up areas accounts for $30-80 \%$ of the cover. Impervious fraction accounts 20-70 percent of the cover. Single housing units comes under this category. Population will be lower than high intensity residential area.

- 32. High-Intensity Residential: Extremely developed areas where people live in more number comes under this category. Apartment complexes and row houses are the best examples of this category. Pervious fraction accounts for less than 20 percent of the cover. Impervious fraction accounts for $80-100 \%$ of the cover.

- 33. Commercial, Industrial and Transportation: This includes infrastructure that is railways, roads etc. and extremely developed areas which are not classified as high intensity residential.

\section{STUDY AREA}

Chandigarh, the capital city of the Indian states of Punjab and Haryana, lies between the latitudes of $30^{\circ} 44^{\prime} 14 \mathrm{~N}$ and longitudes of $76^{\circ} 47^{\prime} 14 \mathrm{E}$ (Figure 1). It is the first planned city of India designed by French architect Le Corbusier. It covers an area of 114 sq. km. It is surrounded on the north and west by Punjab and east and south by Haryana. Chandigarh and its surrounding area were established as a union territory of India on 1st November, 1966. In Chandigarh, transportation, communication facilities, education and health facilities are highly good.

Chandigarh comes under Koeppen's CWG category that means it has cold dry winter, hot summer and sub-tropical monsoon. Evaporation generally exceeds precipitation and the weather is generally dry. Generally, Chandigarh experiences four seasons.

The summer season is long with the infrequent drizzles or thunder storms. May and June are the hottest months of the year with the mean daily maximum \& minimum temperatures being about $37^{\circ} \mathrm{C} \& 25^{\circ} \mathrm{C}$, respectively. Maximum temperatures can rise up to $44^{\circ} \mathrm{C}$. Southwest monsoons with high intensity showers commence in late June. The weather at this time is hot and humid. The variation in annual rainfall on year basis is appreciable i.e $700 \mathrm{~mm}$ to $1200 \mathrm{~mm}$. The 20 year average rainfall for Chandigarh is $1100.7 \mathrm{~mm}$. the winter season generally starts from the month of October and December and January are the coldest months. The temperature sometimes dips o below 5 degrees in the month of January.

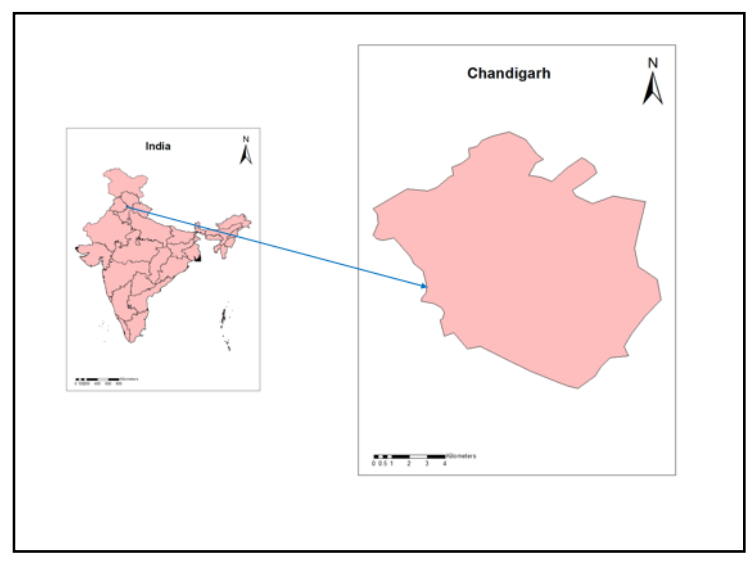

Figure 1 Study Area 


\section{MATERIALS AND METHODS}

\subsection{Data Used}

WRF Model has an inbuilt global geographical database dating back to 1992-93. So, there is a need to integrate WRF compatible updated datasets. As a result, updated land surface parameters, modified LULC and high resolution digital elevation model (DEM) have been integrated into the model.

Table 1 shows the datasets used for the study along with their resolution.

\section{TABLE 1 DATASET USED}

\begin{tabular}{|c|c|}
\hline DATASETS & RESOLUTION \\
\hline SRTM-DEM & $90 \mathrm{~m}$ \\
\hline $\begin{array}{c}\text { Urban LULC (prepared } \\
\text { from)Resourcesat-2 LISS- IV }\end{array}$ & $5.8 \mathrm{~m}$ \\
\hline Albedo & $1 \mathrm{~km}$ \\
\hline Green Fraction & $1 \mathrm{~km}$ \\
\hline $\begin{array}{c}\text { NCEP GFS data (every 3hrs.) } \\
\text { http://rda.ucar.edu/datasets/ } \\
\text { ds084.1/ }\end{array}$ & $500 \mathrm{~m}$ \\
\hline
\end{tabular}

\subsection{Ground Observation Data}

Validation was carried out using ground observation data obtained from Regional Meteorological centre, Delhi, Indian Meteorological Department (IMD) of Chandigarh. IMD provided point observation data for every three hours for the simulation period of meteorological surface parameters of Rainfall, Temperature, RH and Wind speed on three hourly basis.

\subsection{Domain Configuration}

Figure 2 shows the two domains, which were configured in the WRF Model having the spatial resolution of 3KM and $1 \mathrm{KM}$. The grid points in each of the domain were set to be $257 * 239$ and $209 * 201$ respectively with the innermost domain d02 containing study area of Chandigarh. The Initial and boundary conditions for the meteorological fields were provided from the National GFS $0.25^{\circ}$ six hourly data.

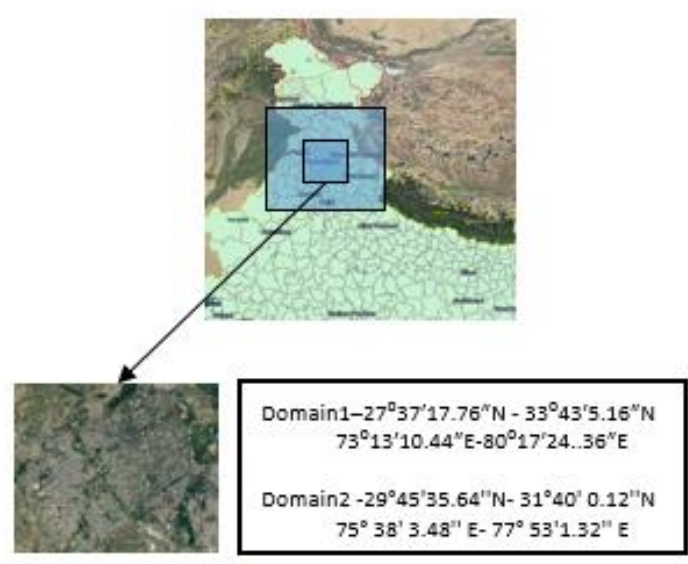

Figure 2. Domain Configuration

\subsection{Physics Schemes}

There are various options for physical parameterizations of key boundary layer phenomena in this model for (i) microphysics, (ii) cumulus parameterization (CP), (iii) surface layer (SL), (iv) Land Surface Model (LSM), (v) Planetary Boundary Layer (PBL), and Long wave\& Shortwave Radiation. The present study captures all of the above physical parameterizations in various options representing all of these six categories.

A summary of the physics options used in this study has been listed in Table 2 .

TABLE 2 PHYSICS SCHEMES USED IN THIS STUDY

\begin{tabular}{|c|c|}
\hline PHYSICS & ALL DOMAINS \\
\hline Micro Physics & WSM6 \\
\hline $\begin{array}{l}\text { Long Wave Radiation } \\
\text { Scheme }\end{array}$ & RRTM \\
\hline $\begin{array}{c}\text { Short Wave Radiation } \\
\text { Scheme }\end{array}$ & Dudhia \\
\hline $\begin{array}{c}\text { Surface } \\
\text { Layer(sf_sfclay_phyiscs) }\end{array}$ & $\begin{array}{l}\text { Monin-Obukhov(Janjic } \\
\text { Eta) scheme }\end{array}$ \\
\hline $\begin{array}{l}\text { Land Surface Physics } \\
\text { (sf_surface_physics) }\end{array}$ & $\begin{array}{c}\text { Unified Noah land surface } \\
\text { model }\end{array}$ \\
\hline $\begin{array}{c}\text { PBL } \\
\text { scheme(bl_pbl_physics) }\end{array}$ & $\begin{array}{l}\text { Mellor-Yamada-Janjic } \\
\text { scheme }\end{array}$ \\
\hline $\begin{array}{l}\text { Urban surface physics } \\
\text { (sf_urban_physics) }\end{array}$ & $\begin{array}{c}\text { BP,SLUCM,BEP,BEP+B } \\
\text { EM }\end{array}$ \\
\hline
\end{tabular}




\subsection{Methodology}

The methodology adopted can be divided into five broad steps. The first step involves generation of 3-class Urban LULC from Resourcesat-2 LISSIV data. Further, the generated urban LULC and other land surface parameters were ingested in the model and then model simulations were carried out. Further, the model outputs were validated with respect to ground observation data.

\subsubsection{Generation of 3- Class Urban LULC}

The three class urban LULC map of Chandigarh was prepared by Dastidar, 2011 at IIRS, Dehradun. Resourcesat-2 LISS IV data was utilized for generation of this map. The LISS-IV sensor is having spatial resolution of $5.8 \mathrm{~m}$ at nadir. After performing the supervised classification, vectorization was done and then $100 \mathrm{~m} \mathrm{x}$ $100 \mathrm{~m}$ fishnet was overlaid on the classified vector image. By using Dominant approach percentage of built-up area in each grid cell was computed. If the percentage is more than $80 \%$, it was classified as high intensity residential and if the percentage is less than $80 \%$, it was classified as low intensity residential. After classification of three built-up classes, they have been further converted into WRF compatible inputs (Li, Bou-zeid, Barlage, Chen, \& Smith, 2013). The modified urban LULC with three urban built up classes which are High Intensity Residential, Low Intensity Residential and Commercial/Industrial/Transportation.

\section{Ingestion of three class urban LULC into WRF Model}

The three class urban LULC was ingested into the WRF model using composite approach(Li et al., 2013). According to that suitable changes were made in GEOGRID.TBL and namelist. wps. The inner most domain uses new dataset. The outer domain area uses default dataset.

\subsubsection{Ingestion of High Resolution DEM into WRF Model}

The SRTM_90m DEM file was converted into WRF Compatible binary format in LINUX and it has renamed as "00000.number of columns-00000.number of rows". An index file was also created and in GEOGRID.TBL, a new entry was created in existing HGT_M. namelist.wps was also updated according to the new DEM. Similarly, all other LSPs were also ingested in WRF model by creating index file and entry in GEOGRID.TBL.

\subsubsection{Model Simulations}

In this study three days in the month of august were selected for the simulations those are August $19^{\text {th }}$ to $22^{\text {nd, }}$ 2017 with modified LULC, and High resolution DEM using FNL $\left(0.25^{\circ}\right)$ meteorological data. After ingestion of all geographic data in WRF and necessary changes, the simulations were run for the above period. The model outputs were extracted and then were further analysed. 3.5.5 Validation of Model results

Validation of model results were carried out by using the ground surface observation data obtained from IMD as described in section 3.2.

\section{RESULTS AND DISCUSSION}

\subsection{Temperature}

Figure 3 shows the spatial distribution of temperature at 2 $\mathrm{m}$ simulated with four Urban physics schemes over d02 on August $19^{\text {th }} 11: 30$ IST. BEP and BEP+BEM showed better spatial distribution than Bulk and SLUCM schemes. The temperature range for both the physics options is seen in between $9-36^{\circ} \mathrm{C}$

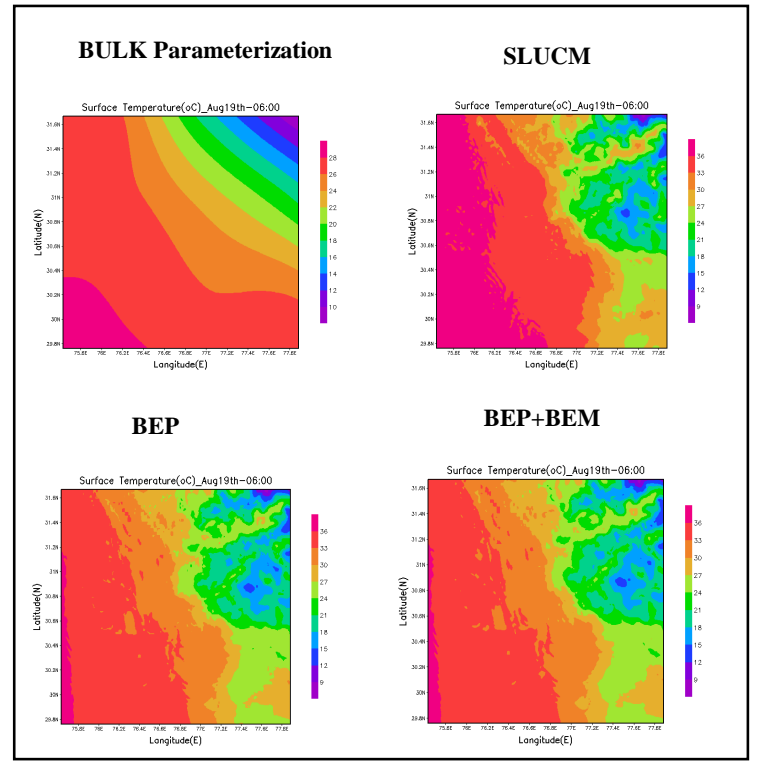

Figure 3: Spatial distribution of Temperature at $2 \mathrm{~m}$ with four Urban physics schemes over d02 on August $19^{\text {th }}$ 11:30 IST

\subsection{Relative Humidity}

Figure 4 shows the spatial distribution of relative humidity simulated with four Urban physics schemes over d02 on August 19 ${ }^{\text {th }} 11: 30$ IST. The figures depicts clearly that bulk parameterization did not show much of the spatial variation, however urban phyiscs schemes provided better spatial variablility. BEP+BEM showed similar results in terms of spatial distribution. The relative humidity range for BEP+BEM is seen in between 45$100 \%$. 


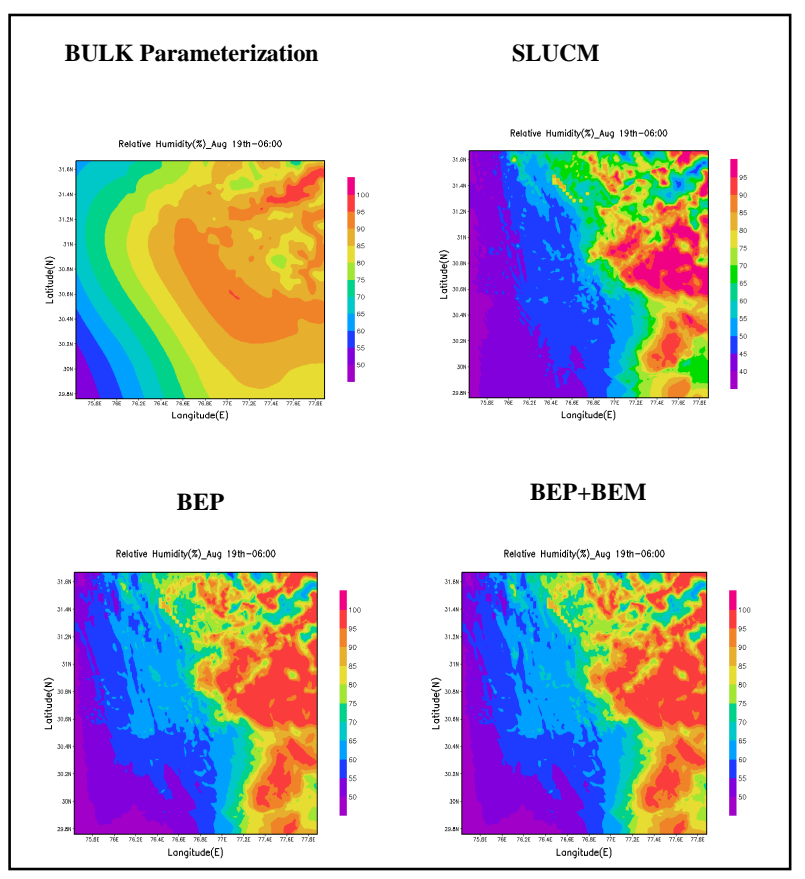

Figure 4. Spatial distribution of Relative Humidity with four Urban physics schemes over d02 on August $19^{\text {th }}$ 11:30 IST

\subsection{Wind Speed}

Figure 5 shows Spatial distribution of Wind Speed with all urban physics schmes over d02 on August $19^{\text {th }} 11: 30$ IST. BEP and BEP+BEM showed similar results in terms of spatial distribution. The wind speed range for both the physics options is seen in between 1-12 m/s. In terms of wind speed also bulk parameterization did not show much of spatial variability.

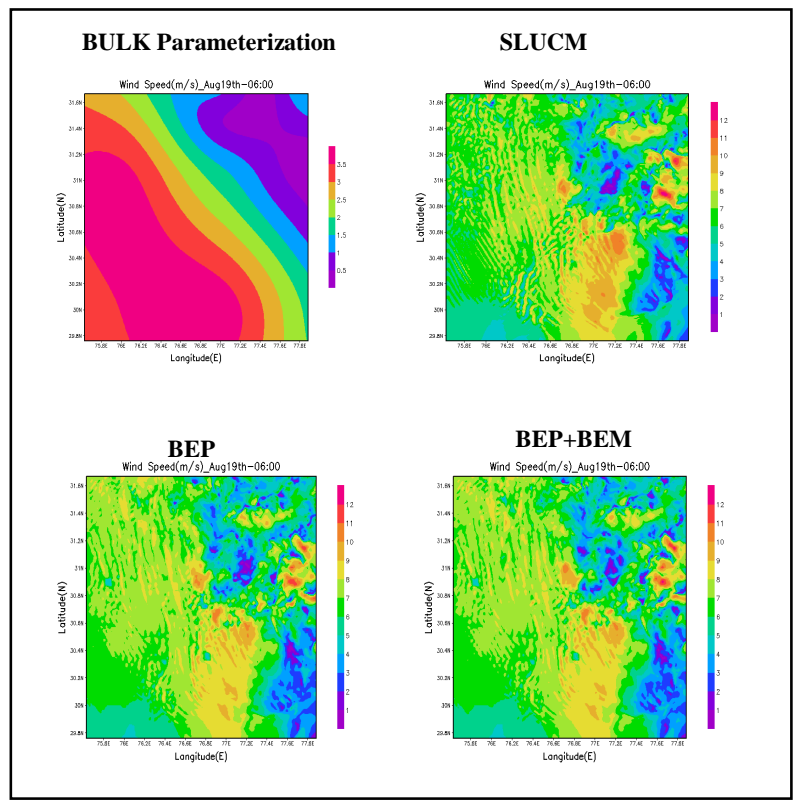

Figure 5. Spatial distribution of Wind Speed with four Urban physics schmes over d02 on August $19^{\text {th }} 11: 30$ IST

\subsection{Single Built-up and 3-Class Urban LULC:}

Figure 6 shows, Spatial distribution of Temperature, Relative Humidity and Wind Speed with single class urban built up and three class urban LULC d02 on August $19^{\text {th }} 11: 30$ IST. Three class urban LULC is showing more spatial distribution than single class urban built-up. Three class urban LULC is able to capture the urban heterogeneity of the Chandigarh city in an improved manner.

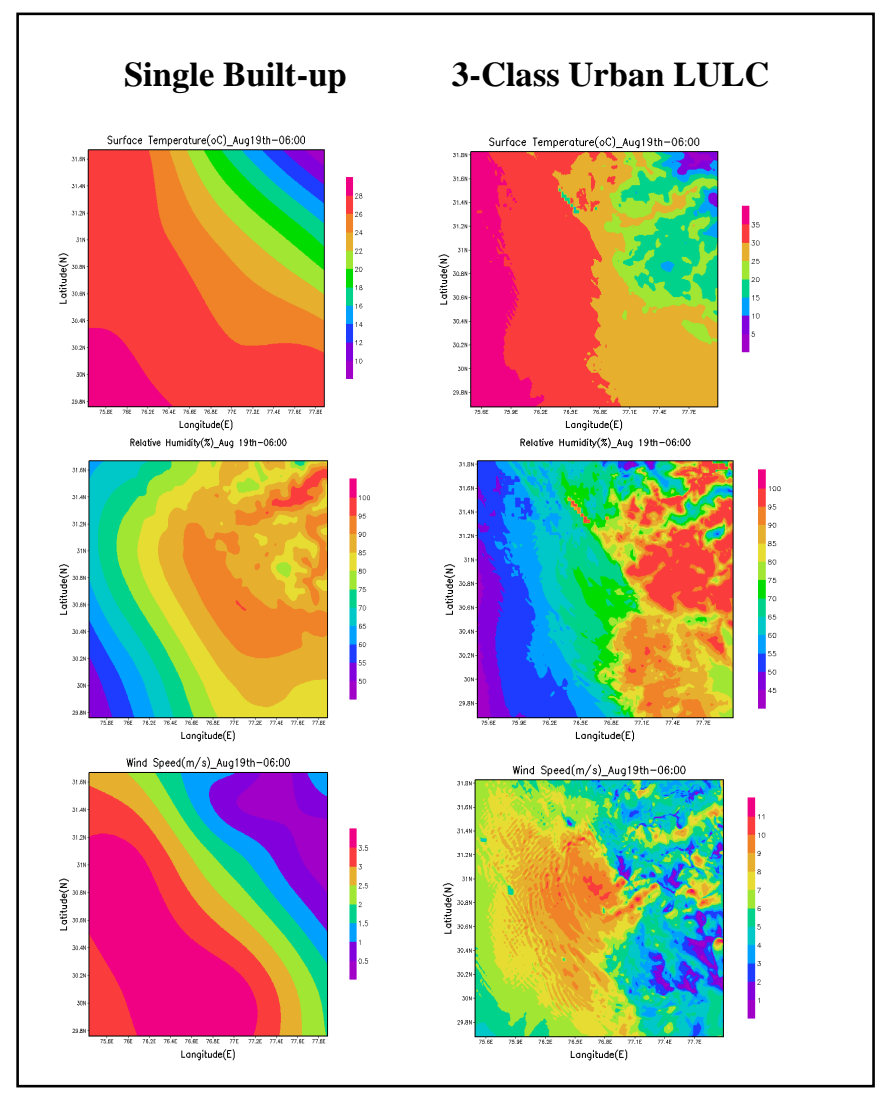

Figure 6. Spatial distribution of Temperature, Relative Humidity and Wind Speed with single class urban built up and three class urban LULC d02 on August 19 ${ }^{\text {th }} 11: 30$ IST

\subsection{Validation}

The simulated results were validated with observed IMD data (Ground Observation Data). Figure 7 clearly shows that bulk parameterization has failed to take in to account of the variability of land surface characteristics of the domain and is quite far from ground observed data. SLUCM is given better results as compared to Bulk Parameterization. But out of all schemes, BEP and $\mathrm{BEP}+\mathrm{BEM}$ provided the best results in terms of temperature, relative humidity and wind speed. The validated results of temperature at $2 \mathrm{~m}$, relative humidity and wind speed for all seasons with ground observed data are shown in Fig. 7 A, B and C respectively. 

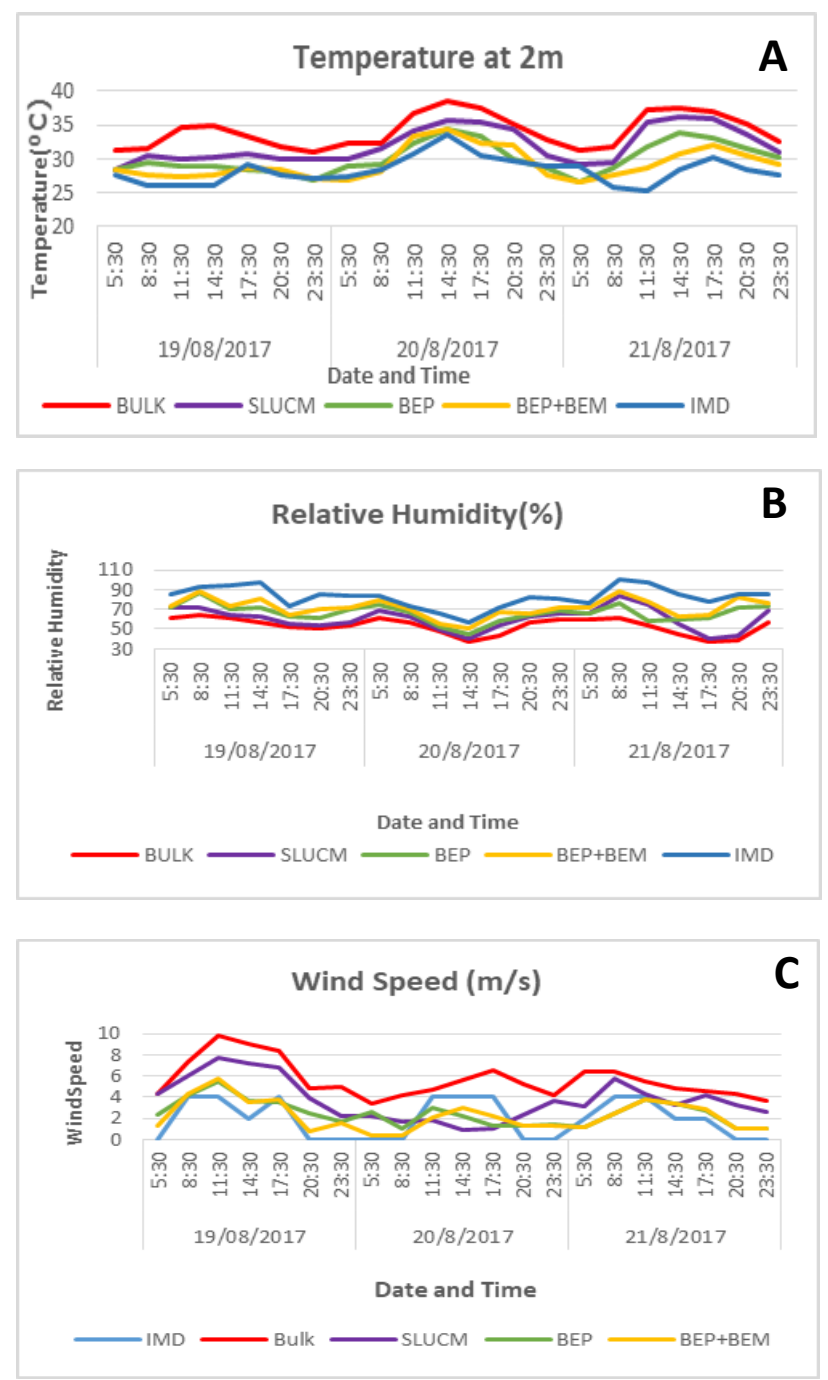

Figure 7. Comparison between observed and simulated A)

Temperature B) Relative Humidity C) Wind Speed

Figure 8 shows comparison between observed and simulated A) Temperature B) Relative Humidity C) Wind Speed with single built up class and three class urban LULC. Here three class urban LULC is giving better results than single built up class. These three classes captured the heterogeneity of the city over the study area and it is in close consent with the ground observational data.

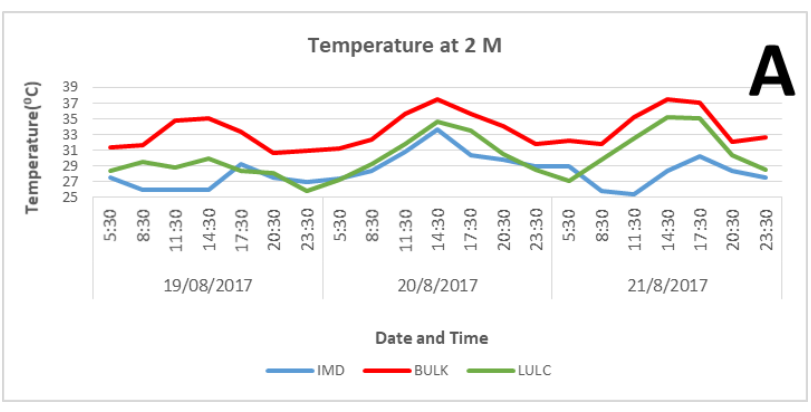

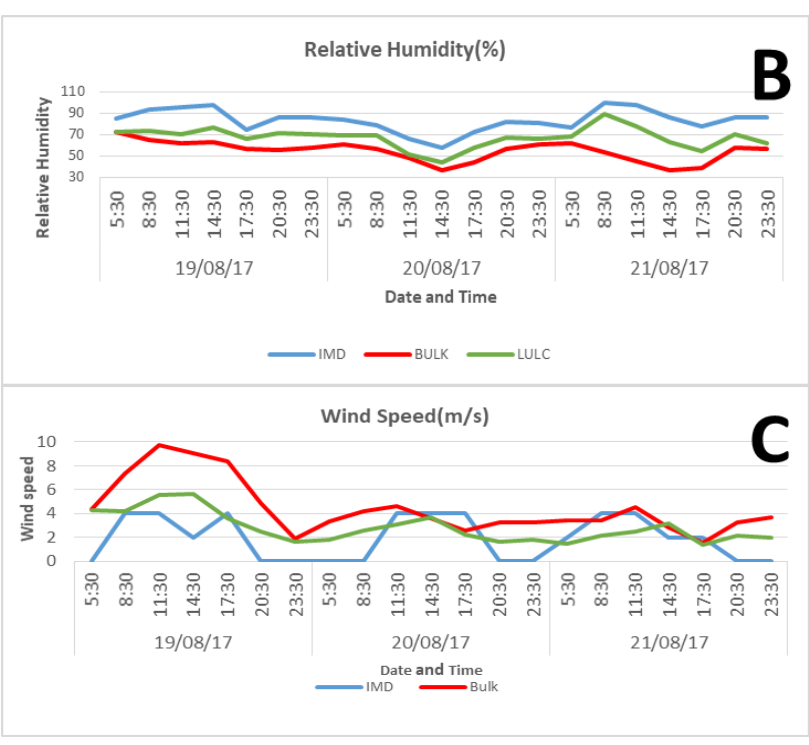

Figure 8 Comparison between observed and simulated A) Temperature B) Relative Humidity C) Wind Speed with single built up class and three class urban LULC

Table 3 presents the statistical analysis of results. WRF Model overestimated the mean temperature with all schemes (Bulk Parameterization: $32.66{ }^{\circ} \mathrm{C}$, SLUCM: $29.82^{\circ} \mathrm{C}$, BEP: $28.29^{\circ} \mathrm{C}$ and BEP+BEM: $27.85^{\circ} \mathrm{C}$ ) are larger than observed mean temperature of $27.05^{\circ} \mathrm{C}$, however, the $\mathrm{BEP}+\mathrm{BEM}$ scheme $\left(27.85^{\circ} \mathrm{C}\right)$ is closer to the mean observed temperature $\left(27.05^{\circ} \mathrm{C}\right)$. Out of all urban physics schemes, Bulk parameterization overestimated the temperature value due to missing information of urban fluxes. BEP+BEM has provided acceptable results, because it has taken into account of urban fluxes and energy exchanges and 3D parameters in urban parameter table. The RMSE of Bulk Parameterization is very high i.e, $6.02^{\circ} \mathrm{C}$. In general BEP+BEM gave better results for temperature at $2 \mathrm{~m}$ with a RMSE of $1.11^{\circ} \mathrm{C}$ and MAE of $0.79^{\circ} \mathrm{C}$

In terms of relative humidity, WRF Model underestimated the result and the mean of the simulated relative humidity of all schemes (Bulk Parameterization: 58.04\%, SLUCM: 61.23\%, BEP: $67.39 \%$ and

BEP+BEM: $78.48 \%$ ) are lower than observed mean of $88 \%$. Out of all physics schemes, Bulk parameterization underestimated the relative humidity the most with an RMSE of 9.73. Again here, BEP+BEM gave best results for relative humidity with a RMSE of 4.39.

In general BEP+BEM gave better results for Wind speed with a RMSE of $2.62 \mathrm{~m} / \mathrm{s}$ and MAE of $1.58 \mathrm{~m} / \mathrm{s}$. In terms of wind speed, even with the all urban physics option, model has largely overestimated the wind speed. The mean wind speed of all urban physics schemes (Bulk Parameterization: $6.51 \mathrm{~m} / \mathrm{s}$, SLUCM: $5.59 \mathrm{~m} / \mathrm{s}$, BEP: 3.62 $\mathrm{m} / \mathrm{s}$ and BEP+BEM: $3.58 \mathrm{~m} / \mathrm{s}$ ) are much higher than observed mean of $1.9 \mathrm{~m} / \mathrm{s}$. 
Hence, it is observed that BEP+BEM scheme has provided the best results and the bulk parameterization has largely failed in representing the urban area weather conditions by a large margin.

Table 3 Validation of the simulated results of T2

\begin{tabular}{|c|c|c|c|c|c|}
\hline \multirow{2}{*}{$\begin{array}{l}\text { Physics } \\
\text { options }\end{array}$} & \multicolumn{5}{|c|}{ Temperature at $2 \mathrm{~m}$} \\
\hline & RMSE & MAE & MEAN & $\begin{array}{l}\text { STD } \\
\text { DEV }\end{array}$ & Correlation \\
\hline IMD & & & 27.05 & 1.19 & \\
\hline BULK & 6.02 & 5.60 & 32.66 & 1.69 & 0.22 \\
\hline SLUCM & 3.09 & 2.76 & 29.82 & 0.84 & 0.31 \\
\hline BEP & 2.14 & 1.24 & 28.29 & 1.17 & 0.51 \\
\hline \multirow[t]{2}{*}{ BEP+BEM } & 1.11 & 0.79 & 27.85 & 1.54 & 0.67 \\
\hline & \multicolumn{5}{|c|}{ Relative Humidity (\%) } \\
\hline IMD & & & 87.71 & 7.95 & \\
\hline BULK & 9.73 & 5.32 & 58.04 & 4.10 & 0.28 \\
\hline SLUCM & 8.67 & 4.98 & 61.23 & 6.33 & 0.43 \\
\hline BEP & 4.51 & 2.39 & 67.39 & 4.18 & 0.59 \\
\hline \multirow[t]{2}{*}{ BEP+BEM } & 4.39 & 2.49 & 78.48 & 7.51 & 0.78 \\
\hline & \multicolumn{5}{|c|}{ Wind Speed(m/s) } \\
\hline IMD & & & 2 & 2 & \\
\hline BULK & 4.76 & 4.50 & 6.51 & 2.88 & 0.18 \\
\hline SLUCM & 3.72 & 3.59 & 5.59 & 1.77 & 0.32 \\
\hline BEP & 2.98 & 1.62 & 3.62 & 1.26 & 0.34 \\
\hline BEP+BEM & 2.62 & 1.58 & 3.58 & 1.53 & 0.56 \\
\hline
\end{tabular}

Table 4 presents the validation results for Temperature at $2 \mathrm{~m}$, Relative humidity and Wind Speed for single urban built-up class and 3-class urban LULC. The model has overestimated the mean temperature with single class: $33.52^{\circ} \mathrm{C}$ and 3 - class urban LULC: $30.14^{\circ} \mathrm{Cwhich}$ is higher than observed mean of $27.05^{\circ} \mathrm{C}$. In terms of relative humidity model has underestimated the $\mathrm{RH}$. The mean relative humidity of Single class LULC is $54.38 \%$ whereas it is $67.02 \%$ with 3 class urban LULC. It is lower than the observed mean of $87.71 \%$ of IMD data. However, it is closer than the single class LULC results.
In terms of Wind speed the model has overestimated the mean wind speed for single class LULC $(4.43 \mathrm{~m} / \mathrm{s})$ and 3class urban ULC $(2.80 \mathrm{~m} / \mathrm{s})$ which is higher than observed wind speed mean of $2 \mathrm{~m} / \mathrm{s}$. 3-class LULC has been given better results than Single Built-up class and it is closer to the observed mean. RMSE values for temperature, relative humidity and wind speed for 3-class LULC LULC are $0.91^{\circ} \mathrm{C}, 2.63 \%$ and ${ }^{\circ} .82 \mathrm{~m} / \mathrm{s}$ respectively. This results clearly shows that ingestion of 3-class urban LULC has further improved the model results.

Table 4: Validation of the simulated results of T2, Relative Humidity and Wind Speed $(\mathrm{m} / \mathrm{s})$

\begin{tabular}{|c|c|c|c|c|}
\hline \multirow{6}{*}{$\begin{array}{l}\text { Temperature }\left({ }^{\circ} \mathrm{C}\right. \\
\text { ) at } 2 \mathrm{~m}\end{array}$} & & IMD & $\begin{array}{l}\text { Single } \\
\text { Built-Up }\end{array}$ & LULC \\
\hline & RMSE & & 5.67 & 0.91 \\
\hline & MAE & & 5.26 & 1.52 \\
\hline & MEAN & 27.05 & 33.52 & 30.14 \\
\hline & STDV & 1.19 & 2.23 & 2.68 \\
\hline & Correlation & & 0.32 & 0.75 \\
\hline \multirow{5}{*}{$\begin{array}{l}\text { Relative } \\
\text { Humidity (\%) }\end{array}$} & RMSE & & 8.83 & 2.63 \\
\hline & MAE & & 4.57 & 2.23 \\
\hline & MEAN & 87.71 & 54.38 & 67.02 \\
\hline & STDV & 7.95 & 5.60 & 9.75 \\
\hline & Correlation & & 0.38 & 0.89 \\
\hline \multirow{5}{*}{ Wind Speed $(\mathrm{m} / \mathrm{s})$} & RMSE & & 3.37 & 1.82 \\
\hline & MAE & & 2.53 & 0.89 \\
\hline & MEAN & 2 & 4.43 & 2.80 \\
\hline & STDV & 2 & 2.26 & 1.26 \\
\hline & Correlation & & 0.23 & 0.52 \\
\hline
\end{tabular}

\section{CONCLUSION}

In this study, the UCMs integrated in WRF model has been evaluated along with the impact of single urban built-up class and 3 -class urban LULC on model results. The validation of the model outputs were carried out with respect to ground observation data which is provided by Indian Meteorological Department Chandigarh. Out of all urban physics schemes, BEP+BEM urban physics scheme has provided the best results with least RMSE for all variables such as $1.11^{\circ} \mathrm{C}, 4.39 \%$ and $2.62 \mathrm{~m} / \mathrm{s}$ for temperature, relative humidity and wind speed respectively. Bulk Parameterization fails to model the diurnal pattern of temperature accurately and the RMSE values of temperature, relative humidity and wind speed are $6.02{ }^{\circ} \mathrm{C}, 9.73 \%$ and $2.62 \mathrm{~m} / \mathrm{s}$ respectively, which is quite high to be acceptable. Merely integration of urban physics schemes or UCMs has brought significant 
improvement in simulated results. Hence, it is recommended for the BEP+BEM physics scheme should be for the Chandigarh region.

In default Land Use and Land cover data, urban area is represented as a single class. It is understood the urban area is heterogeneous in nature, for improving the model predicted values of climatic variables within a city, high number of classes required. For satisfying this point in this study, three class urban LULC has been ingested to the Model. It has been found that 3-class urban LULC provided better results than default single class LULC.

\section{REFERENCES}

Chen, F., Bornstein, R., \& Ching, J. (2011). The Integrated WRF / Urban Modeling System: Development, Evaluation, and Applications to Urban Environmental Problems, 1-38.

Dastidar, P. G. and Gupta Kshama (2017). Urban Climate Analysis Using High Resolution WRF Model, Indian Institute of remote sensing, M. Tech. Thesis (Unpublished Report)

Epa, U. S., \& EPA. (2008). Reducing Urban Heat Islands: Compendium of Strategies Urban Heat Island Basics, 122. Retrieved from http://www.epa.gov/heatisland/resources/pdf/BasicsComp endium.pdf\%5Cnhttp://www.epa.gov/heatisland/about/ind ex.htm\%5Cnpapers2://publication/uuid/E82A9E0CE51A-400D-A7EE-877DF661C830

Garratt, J. R. (1990). Boundary layer climates. EarthScience Reviews (Vol. 27). https://doi.org/10.1016/00128252 (90)90005-G

Grell, G. A., \& Dévényi, D. (2002). A generalized approach to parameterizing convection combining ensemble and data assimilation techniques. Geophysical Research Letters, 29(14), 38-1-38-4. https://doi.org/10.1029/2002GL015311

Jandaghian, Z., Touchaei, A. G., \& Akbari, H. (2017). Sensitivity analysis of physical parameterizations in WRF for urban climate simulations and heat island mitigation in Montreal. Urban Climate, (October), 0-1. https://doi.org/10.1016/j.uclim.2017.10.004

Kan, Y., Liu, C., Liu, Y., \& Zhou, C. (2015). Evaluation of WRF microphysics and cumulus parameterization schemes in simulating a heavy rainfall event over Yangtze River delta, (September), 96100R. https://doi.org/10.1117/12.2185766

Khain, A., Lynn, B., \& Dudhia, J. (2010). Aerosol Effects on Intensity of Landfalling Hurricanes as Seen from
Simulations with the WRF Model with Spectral Bin Microphysics. Journal of the Atmospheric Sciences, 67(2), 365-384. https://doi.org/10.1175/2009JAS3210.1

Klemp, J. B., Gill, D. O., Barker, D. M., Duda, M. G., Wang, W., \& Powers, J. G. (2008). A Description of the Advanced Research WRF Version 3, (June).

Of, J., Meteorology, A., \& Studies, M. M. (2004). The Kain-Fritsch Convective Parameterization: An Update, (1980), 170-181.

Yubao Liu, Fei Chen, Thomas Warner and Jeffrey Basara,(2005). Verification of a Mesoscale DataAssimilation and Forecasting System for the Oklahoma City Area During the Joint Urban 2003 Field Project.2004

Pielke, R. A., Marland, G., Betts, R. A., Chase, T. N., Eastman, J. L., Niles, J. O., ... Running, S. (2002). The influence of land-use change and landscape dynamics on the climate system- relevance to climate change policy beyond the radiative effect of greenhouse gases. Philosophical Transactions of the Royal Society A, 360, 1705-1719.

Skamarock, W. C., Klemp, J. B., Dudhi, J., Gill, D. O., Barker, D. M., Duda, M. G. ... Powers, J. G. (2008). A Description of the Advanced Research WRF Version 3. Technical Report, (June), 113. https://doi.org/10.5065/D6DZ069T

Tewari, M., Chen, F., \& Kusaka, H. (2004). Implementation and Evaluation of a Single - Layer Urban Canopy Model in WRF / Noah.

Tewari, M., Chen, F., Kusaka, H., \& Miao, S. (2007). Coupled WRF/Unified Noah/urban-canopy modeling system. NCAR WRF Documentation, NCAR, Boulder, 122.

UCAR. (2008). Chapter 3: WRF Pre-processing System (WPS), 1-26.Retrieved from http://www2.mmm.ucar.edu/wrf/users/docs/user_guide_V 3/users_guide_chap3.htm 